PHYSICAL REVIEW D 94, 119901(E) (2016)

\title{
Erratum: Improved separation of soft and hard components in multiple Coulomb scattering \\ [Phys. Rev. D 93, 036008 (2016)]
}

M. V. Bondarenco

(Received 19 December 2016; published 30 December 2016)

DOI: 10.1103/PhysRevD.94.119901

The second line below Eq. (21) should read " ...k $k=2$...."

The second line of the caption for Fig. 1 should read "... projected angle distribution ...."

Axes labels for Fig. 2 should read $\mathfrak{R e} \kappa$ and $\mathfrak{I} \mathfrak{m} \kappa$. 